\title{
Urbanisation, nutrition transition and cardiometabolic risk: the Benin study
}

\author{
Hélène Delisle $^{1 *}$, Gervais Ntandou-Bouzitou ${ }^{2}$, Victoire Agueh ${ }^{3}$, Roger Sodjinou ${ }^{4}$ and Benjamin Fayomi ${ }^{5}$ \\ ${ }^{1}$ Department of Nutrition, Faculty of Medicine, TRANSNUT, WHO Collaborating Centre on Nutrition Changes and \\ Development, University of Montreal, PO Box 6128, Downtown Station, Montreal, PQ, Canada H3C $3 J 7$ \\ ${ }^{2}$ Bioversity International, West and Central Africa, C/o IITA, 08 BP 0932, Cotonou, Benin \\ ${ }^{3}$ Institut Régional de Santé Publique (IRSP), Université d'Abomey Calavi, Ouidah, Benin \\ ${ }^{4}$ UNICEF N'Djamena, Chad Country Office, BP 1146, N'Djamena, Chad \\ ${ }^{5}$ Institut de Sciences Biomédicales Appliquées (ISBA), Cotonou, Benin
}

(Submitted 15 March 2011 - Final revision received 29 June 2011 - Accepted 20 July 2011 - First published online 25 November 2011)

\section{Abstract}

A rising prevalence of CVD and diabetes has been observed in sub-Saharan Africa, particularly in cities. The aim of the present study conducted in Benin was to examine the mediating role of nutrition transition in the relationship of urbanisation level and socio-economic status (SES) to cardiometabolic risk markers. A total of 541 subjects in apparent good health were randomly selected from the main city of Cotonou, a small town and its surrounding rural areas. SES was assessed based on a proxy for income and on education. Dietary intake and physical activity were assessed with at least two non-consecutive $24 \mathrm{~h}$ recalls. Scores for micronutrient adequacy and preventive diet were used as indicators of diet quality. Cardiometabolic risk markers were BMI, waist circumference (WC), blood pressure, serum cholesterol and insulin resistance according to homeostasis model assessment. A more advanced stage of nutrition transition, which correlated with lower diet quality scores and less physical activity, was observed in the large city compared with less urbanised locations. More obesity and more adverse cholesterol profiles, but also lower blood pressure, were present in the large city. Urbanisation, income, sedentary lifestyle and alcohol consumption, but not diet quality, independently contributed to higher BMI and WC. Higher micronutrient adequacy was independently associated with a better cholesterol profile. The study confirmed the positive rural-urban gradient in nutrition transition and cardiometabolic risk, except for blood pressure. This risk could be mitigated by a more adequate diet, particularly micronutrient intake, and a more active lifestyle.

Key words: Nutrition transition and diet quality: Urbanisation: Cardiometabolic risk: Sub-Saharan Africa

Nutrition transition, characterised by the progressive shift from a traditional diet rich in fibre and low in fat and sugar to a diet rich in animal products, refined grains, fats, salt and sugar but low in fibre, tends to increase the burden of chronic diseases in developing countries ${ }^{(1,2)}$. Rapid urbanisation, economic growth, technological advances and globalisation, which cause changes in eating patterns and lifestyles, are identified as key drivers of this transition ${ }^{(3)}$. Furthermore, undernutrition early in life, and perhaps as well past or present micronutrient deficiencies, which persist in developing countries, may also contribute to the risk of nutrition-related chronic diseases $^{(4,5)}$, accentuating the double burden of malnutrition (or 'dysnutrition' to encompass all forms of malnutrition) ${ }^{(6)}$ and its detrimental effects on health and health systems in developing countries ${ }^{(7)}$.

While nutrition transition and its links with chronic diseases are well documented in Latin America and Asia ${ }^{(8-12)}$, it remains a little-studied subject in sub-Saharan Africa, except possibly for South Africa ${ }^{(2,13-16)}$. In Benin, two studies ${ }^{(17,18)}$, including one in a poor neighbourhood of the main city of Cotonou $^{(18)}$, have reported the existence of the double burden of malnutrition in households. A more in-depth study of diet, lifestyle and cardiometabolic risk was carried out by our group in Cotonou, a small town (Ouidah) and the latter's rural outskirts, and some results have been published ${ }^{(19-22)}$. In the main city, subjects retained much of their traditional diet despite adopting certain Western eating habits. Obesity increased with urbanisation and socioeconomic status (SES), and physical activity was protective. The metabolic syndrome, and particularly obesity and low HDL-cholesterol (HDL-C), was more highly prevalent in the main city than in Ouidah and its rural outskirts ${ }^{(22)}$.

The primary aim of the present paper was to further explore the role of diet as a key lifestyle variable in mediating the

Abbreviations: HDL-C, HDL-cholesterol; HOMA, homeostasis model assessment; SES, socio-economic status; TC, total cholesterol; WC, waist circumference. 
relationships of urbanisation and SES (main exposure variables) to cardiometabolic risk markers as outcomes. The secondary aim was to describe diet quality in the context of nutrition transition in Benin from a dual perspective of the prevention of nutritional deficiencies and of nutrition-related chronic diseases. The conceptual framework shown in Fig. 1 illustrates the relationships examined in the present study: (1) urbanisation and SES with diet; (2) urbanisation and SES with cardiometabolic risk markers; (3) urbanisation and SES with cardiometabolic risk markers when including diet and other lifestyle variables. The principal hypothesis is that cardiometabolic risk is higher in the main city than in less urbanised locations, independent of SES, by virtue of a more advanced stage of nutrition transition, and hence lower diet quality.

\section{Materials and methods \\ Population and sample}

The study in Benin is part of a larger research project on nutrition transition and its relationship with CVD risk factors in African descent populations living in different settings.

A sample of 541 apparently healthy adults, aged 25-60 years, included 200 subjects from the main city of Cotonou, 171 from the small town of Ouidah $(50 \mathrm{~km}$ away from Cotonou) and 170 from the rural area surrounding Ouidah. The subjects were all Beninese-born adults who had lived in the study area for at least 6 months. Subjects with a prior diagnosis of hypertension, diabetes or CHD were excluded, as they might have changed their diet (and lifestyle) since the diagnosis, while the study was precisely focusing on the relationship of diet and risk factors for these diseases. Sample size determination and details of the sampling procedure have been described elsewhere ${ }^{(19-22)}$. In brief, a three-stage random sampling method was used. In the main city, ten out of the
140 neighbourhoods were randomly selected, and then twenty households per neighbourhood, based on a household list. In each household, only one eligible adult was picked at random, alternating men and women. In the town of Ouidah, five out of the twenty-two neighbourhoods were selected, and in the surrounding rural areas, five out of the thirty-eight villages were selected. Compounds and households within the compounds were given numbers, as there was no household census. In each selected neighbourhood or village, thirty-four households were randomly selected and from each household, one adult was selected.

\section{Socio-economic status and urbanisation}

Data on age, sex and education were collected by personal interviews. Urbanisation level was given by the location of residence - city, town or rural area - using the criteria of the Government of Benin ${ }^{(23)}$. SES was assessed based on education and a household amenity score as a proxy of household income, similar to that of the Demographic and Health Surveys of Benin ${ }^{(24)}$. The income proxy score included the same variables in all three locations, but income tertiles (low, medium and high) calculated separately for each location were used in the analyses. Components of the score included the following: utilities (electricity or running water); ownership of land, motorcycle, car, television, refrigerator and telephone (home phone or cell phone); other household wealth indices such as ownership and type of housing, and energy source for cooking.

\section{Dietary data}

Dietary intake was assessed through two non-consecutive $24 \mathrm{~h}$ food recalls for all subjects. A third recall was conducted for all subjects from the main city and for a third of the subjects from

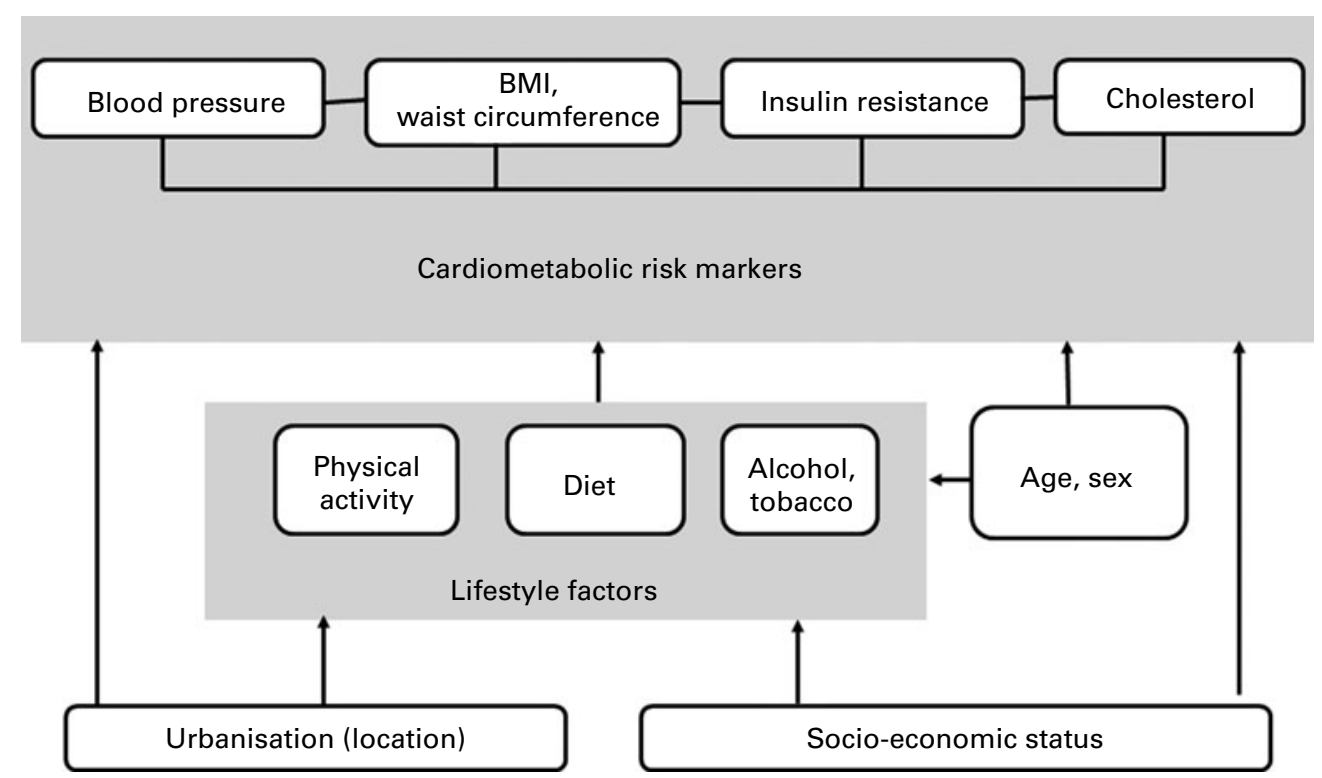

Fig. 1. Conceptual framework of the study. Level of urbanisation (according to location) and socio-economic status are exposure variables; cardiometabolic risk markers are outcome variables; lifestyle factors, in particular diet, are mediating variables, while age and sex are control variables. 
the other locations owing to time and resource constraints. Recalls were conducted over a period of 1 month, and included week- and weekend days. Special celebration days were avoided in order to prevent bias in the assessment of usual food intake. Servings of food consumed were estimated with the help of calibrated local utensils. Consumption was calculated by food groups. Energy and nutrient intakes were computed with WorldFood ${ }^{(25)}$ and additional data were derived from other food composition tables of the region, in particular from Mali ${ }^{(26)}$ and Nigeria ${ }^{(27)}$.

Diet quality was assessed using two complementary scores as designed for international use in previous studies of our group: micronutrient adequacy and preventive $\operatorname{diet}^{(19,28,29)}$. While the former score reflects dietary sufficiency, the latter refers to moderation and balance to prevent obesity and chronic diseases. The micronutrient adequacy score was based on the FAO/WHO's recommended dietary intakes for age and $\operatorname{sex}^{(30)}$, and included ten vitamins $\left(\mathrm{A}, \mathrm{B}_{6}, \mathrm{~B}_{12}, \mathrm{C}\right.$ and $\mathrm{E}$, and thiamin, riboflavin, niacin, pantothenic acid and folate) and four minerals ( $\mathrm{Mg}, \mathrm{Ca}, \mathrm{Fe}$ and $\mathrm{Zn}$ ). For each item, a rating of ' 1 ' was given if the intake met the recommendation and ' 0 ' if it did not. The preventive diet score was based on eight $\mathrm{WHO} / \mathrm{FAO}$ dietary guidelines for the prevention of chronic diseases ${ }^{(31)}$; these included the percentages of total energy supplied by protein, fat, SFA, PUFA and free sugar, and the daily intake of cholesterol $(\mathrm{mg} / \mathrm{d})$, fibre $(\mathrm{g} / \mathrm{d})$, and fruits and vegetables $(\mathrm{g} / \mathrm{d})$. For each item, a rating of ' 1 ' was given if the guideline was met and ' 0 ' if it was not. Since it was not possible to estimate $\mathrm{Na}$ intake, and since specific amounts of PUFA such as $n-3$ and $n-6$ were not available in the food composition tables used, recommendations concerning these nutrients were not considered. Hence, the maximum score for micronutrient adequacy and preventive diet was 14 and 8 , respectively.

\section{Other lifestyle variables}

Physical activity was assessed through recalls of activities performed the previous day ${ }^{(21)}$. As in the case of diet, there were three recalls for all subjects in the large city and for a third of the subjects in the other locations; two recalls were conducted for all other respondents. Depending on the duration and intensity of activities, estimated in metabolic equivalents of task $^{(32)}$, subjects were classified as active $(\geq 3$ metabolic equivalents of task and $\geq 30 \mathrm{~min} / \mathrm{d})$ or inactive $(<30 \mathrm{~min} / \mathrm{d}$ or $<3$ metabolic equivalents of task), following WHO recommendations ${ }^{(33)}$

Smoking (smokers, former smokers and non-smokers) and average alcohol consumption $(\mathrm{g} / \mathrm{d})$ were assessed using a questionnaire based on the STEPwise survey tool developed by the WHO for monitoring chronic diseases ${ }^{(34)}$.

\section{Cardiometabolic risk markers}

Cardiometabolic risk markers included in the present study were BMI, waist circumference (WC), systolic and diastolic blood pressure, HDL-C, total cholesterol:HDL-C (TC:HDL-C) ratio and homeostasis model assessment (HOMA) as the index of insulin resistance ${ }^{(35)}$. Weight, height, WC and blood pressure were measured using standard methods as described previously ${ }^{(20,22)}$. Blood samples were collected after a $12 \mathrm{~h}$ overnight fast and were centrifuged within $2 \mathrm{~h}$. Fasting plasma glucose, and serum lipid fractions and insulin were determined using standard laboratory methods, which have also been described elsewhere ${ }^{(20,22)}$.

\section{Data processing and analysis}

Dietary data were adjusted using C-SIDE (Iowa State University, Ames, IA, USA) (36) to reduce intra-individual variance by taking into account interviewer differences, the number and variation of recall days, and the number of days between recalls. All data were analysed using the Statistical Package for Social Sciences, version 15.0 (SPSS Inc., Chicago, IL, USA). To take account of the sampling effect, a weighting factor was computed for each location as the reverse of the probability of being included in the sample. The weighting factor was calculated as follows:

\author{
Weighting factor $=[(1 / N$ eligible subjects in a household $)$ \\ $\times(N$ selected households/total $N$ households \\ in the neighbourhood or rural village) \\ $\times(N$ neighbourhoods or rural villages \\ selected/total $N$ of neighbourhoods \\ or villages in the zone)].
}

This correction factor was used for descriptive univariate analyses, using the SPSS 'complex sample' module. The $\chi^{2}$ tests, $t$ tests and ANOVA followed by Tukey's post hoc test were used to compare locations and sex. Associations between SES and urbanisation and cardiometabolic risk markers were assessed by multiple linear regression. Diet quality scores (and other lifestyle components) were added to the multivariate model to determine their mediating effect. The level of statistical significance (two-sided) was a $P$ value of $<0 \cdot 05$.

\section{Ethical considerations}

The study was conducted according to the guidelines laid down in the Declaration of Helsinki and all procedures involving human subjects/patients were approved by the Research Ethics Committee of the Faculty of Medicine, University of Montreal, Montreal, Canada, and by the Benin Ministry of Public Health. All study participants signed a written informed consent form after being given oral explanations on the study. Results were given back individually, and participants in whom diabetes or hypertension were suspected were referred for a medical consultation paid by the project. Overall findings of the study were also presented to the whole community and health authorities. 


\section{Results}

\section{Characteristics of the study subjects}

Of the 718 subjects initially contacted, 622 were eligible. Among the non-eligible subjects, forty-two were excluded because of a prior diagnosis of diabetes or hypertension. A total of 541 subjects completed the study. Considering thirty-three refusals, thirty-six dropouts and twelve lost to follow-up, the response rate was $86.9 \%$ (541 out of 622 ).

Mean age of the subjects was 38.1 (SE 0.5 ) years. There was no age difference according to sex or location (Table 1). Education level was not significantly different across locations, but was higher among men than among women in all locations. Respondents of the large city had a more sedentary lifestyle than those of the small town and rural areas, and women were less physically active than men. Smoking was uncommon. Alcohol consumption was higher among men than among women, but was not different across locations.

Diet according to place of residence and socio-economic status

Regarding food groups, consumption of grains, legumes and fish was significantly higher in the rural area and small town than in the main city, while the reverse was observed for dairy products and vegetables. Reported intake of meat/poultry was significantly lower in the rural areas compared with the main city and the small town. Fruit consumption was much higher in the rural area compared with the main city. No difference according to location was detected for the consumption of tubers/roots, eggs, fats/oils and sweets/sweet

Table 1. Characteristics of the study subjects by location and sex (Mean values with their standard errors) drinks. Consumption was higher in men for all food groups except eggs, dairy products, fruits and fats/oils (Table 2).

Diet quality based on both the micronutrient adequacy score and the preventive diet score was significantly better in the rural area and the small town than in the main city, but there was no difference according to sex (Table 3). Overall, the proportion of subjects meeting the recommended dietary intakes for vitamin $\mathrm{B}_{12}, \mathrm{Fe}, \mathrm{Ca}$ and $\mathrm{Zn}$ was generally low. The proportion of subjects achieving the recommended dietary intakes for thiamin, niacin, riboflavin, pantothenic acid, vitamin $\mathrm{B}_{12}, \mathrm{Fe}, \mathrm{Ca}$ and $\mathrm{Zn}$ was significantly lower in the main city, while that of folate was higher, than in the other locations. A higher proportion of women than men met the recommended nutrient intake for vitamins $\mathrm{A}, \mathrm{C}$ and $\mathrm{E}$, while a higher proportion of men met those for folate, Fe and $\mathrm{Zn}$.

Overall, the proportion of subjects who met the preventive diet recommendations for fruit and vegetable intake and for the percentage of energy from PUFA was low (Table 3). We observed that the proportion of subjects meeting the recommendations for fibre intake, PUFA and the percentage of energy from fat was lower in the main city compared with the small town and the rural area. Conversely, the proportion of compliant subjects was higher in the main city for saturated fat, and for fruit and vegetable intake. Regarding sex differences in preventive diet components, a higher proportion of women met the recommendations for fibre intake, and a higher proportion of men for the percentage of total fat and PUFA.

Diet quality based on either score did not differ by income tertile in the rural area or in the small town, while in the main city, the preventive diet score increased with income

\begin{tabular}{|c|c|c|c|c|c|c|c|c|}
\hline & \multirow[b]{2}{*}{$\begin{array}{c}\text { All } \\
(n 541)\end{array}$} & \multicolumn{4}{|c|}{ Location } & \multicolumn{3}{|c|}{ Sex } \\
\hline & & $\begin{array}{l}\text { Rural } \\
(n \text { 170) }\end{array}$ & $\begin{array}{l}\text { Small town } \\
(n 171)\end{array}$ & $\begin{array}{l}\text { Large city } \\
\quad(n 200)\end{array}$ & $P$ & $\begin{array}{l}\text { Men } \\
(n \text { 271) }\end{array}$ & $\begin{array}{l}\text { Women } \\
(n \text { 270) }\end{array}$ & $P$ \\
\hline \multicolumn{9}{|l|}{$\mathrm{Age}^{*}$} \\
\hline Mean & $38 \cdot 1$ & $36 \cdot 3$ & $37 \cdot 9$ & $38 \cdot 2$ & \multirow{2}{*}{ NS } & $36 \cdot 9$ & 39.5 & \multirow[t]{2}{*}{ NS } \\
\hline SEM & 0.5 & $1 \cdot 2$ & 0.7 & 0.6 & & 0.7 & 0.5 & \\
\hline \multicolumn{9}{|l|}{ Education $(\%) \dagger$} \\
\hline None & $16 \cdot 2$ & $30 \cdot 7$ & $20 \cdot 8$ & $15 \cdot 1$ & \multirow[t]{3}{*}{ NS } & $6 \cdot 3$ & $27 \cdot 6$ & \multirow[t]{3}{*}{$<0.001$} \\
\hline Primary school & 31.9 & $32 \cdot 1$ & 35.9 & $31 \cdot 8$ & & $26 \cdot 1$ & 38.5 & \\
\hline Secondary and above & 51.9 & $37 \cdot 2$ & $43 \cdot 3$ & $53 \cdot 1$ & & $67 \cdot 6$ & 33.9 & \\
\hline \multicolumn{9}{|l|}{ Income level (\%)† } \\
\hline Low & $22 \cdot 5$ & $30 \cdot 0$ & $37 \cdot 7$ & 21.5 & \multirow[t]{3}{*}{ NS } & $21 \cdot 2$ & $24 \cdot 0$ & \multirow[t]{3}{*}{ NS } \\
\hline Middle & 44.6 & $16 \cdot 0$ & $30 \cdot 7$ & $47 \cdot 0$ & & $49 \cdot 7$ & $38 \cdot 7$ & \\
\hline High & 32.9 & $54 \cdot 0$ & 31.6 & 31.6 & & $29 \cdot 1$ & $37 \cdot 3$ & \\
\hline \multicolumn{9}{|l|}{ Physical activity (\%)† } \\
\hline Inactive (sedentary) & 35.9 & 4.9 & 6.5 & 38.9 & \multirow[t]{2}{*}{$<0.001$} & $12 \cdot 8$ & $62 \cdot 2$ & \multirow[t]{2}{*}{$<0.001$} \\
\hline Active & $64 \cdot 1$ & $95 \cdot 1$ & 93.5 & $61 \cdot 1$ & & $87 \cdot 2$ & $37 \cdot 8$ & \\
\hline \multicolumn{9}{|l|}{ Tobacco (\%)† } \\
\hline Smoker & 1.8 & 2.5 & 7.9 & 1.6 & \multirow{3}{*}{ NS } & 3.4 & 0.0 & \multirow{3}{*}{$<0.001$} \\
\hline Ex-smoker & 9.5 & $2 \cdot 8$ & $7 \cdot 4$ & $10 \cdot 0$ & & $17 \cdot 3$ & 0.5 & \\
\hline Non-smoker & $88 \cdot 7$ & $94 \cdot 7$ & $84 \cdot 7$ & 88.5 & & $78 \cdot 3$ & 99.5 & \\
\hline \multicolumn{9}{|c|}{ Alcohol intake ( $\mathrm{g} / \mathrm{d}$, all subjects) ${ }^{*}$} \\
\hline Mean & $22 \cdot 3$ & $14 \cdot 8$ & $16 \cdot 1$ & $23 \cdot 1$ & \multirow[t]{2}{*}{ NS } & $28 \cdot 0$ & $15 \cdot 8$ & \multirow[t]{2}{*}{0.002} \\
\hline SEM & $2 \cdot 0$ & 3.9 & 2.5 & $2 \cdot 1$ & & $3 \cdot 0$ & 1.4 & \\
\hline
\end{tabular}

* Weighted data.

†Percentages on weighted data. 
$(P=0.005)$. It was also observed that rural dwellers in the lower-income tertile had better diet quality in terms of both micronutrient adequacy and preventive diet than their low-income counterparts in the main city (data not shown). The preventive diet score increased with income the more urbanised the area is, resulting in a positive and highly significant gradient in the main city $(P<0 \cdot 001)$. While education showed no association with the micronutrient adequacy score, the preventive diet score was positively associated with it, but only in the main city, as shown in Pearson's correlation coefficient ( $r$ 0.294; $P<0.001)$. Income-related differences in food consumption were also significantly higher in the main city compared with the small town and the rural area in univariate analyses (data not shown). Indeed, in the main city, a higher mean consumption of dairy products $(P=0 \cdot 001)$, eggs $(P=0 \cdot 019)$, sweets $(P=0 \cdot 004)$ and vegetables $(P<0.001)$ was observed in the middle and upper tertiles, and a higher meat/poultry consumption $(P<0 \cdot 001)$ in the upper tertile only, compared with the first tertile.

Table 4 provides the standardised $\beta$-coefficients for the multiple linear regression models of food group intake (adjusted for total energy) and diet quality scores on education, income and location, controlling for age and sex. Higher education was positively and independently associated with the intake of dairy products and vegetables, as well as with the preventive diet score. Primary school level was positively associated with fish and oil/fat consumption, compared with non-educated subjects. Higher income (upper tertile) was positively and independently associated with the intake of tubers/roots, meat/poultry and eggs, while it was inversely associated with the intake of grains. Middle income was independently and positively associated with fish/seafood. However, income was not independently associated with diet quality scores when controlling for location.

Residence in the more urbanised area (large city) was positively and independently associated with the intake of meat/ poultry, eggs, dairy products, vegetables and oils/fats, but it was negatively and independently associated with the intake of fish/seafood and fruits. Residence in the main city was also independently related to lower diet quality in terms of micronutrient adequacy and preventive diet, compared with the rural area (Table 4). Residence in the small town was positively associated with meat/poultry and oil/fat consumption, but negatively with fish/seafood and vegetables. Diet quality was similar in the small town and in the rural area.

\section{Cardiometabolic risk markers}

In univariate analyses, BMI and WC were higher in the urban area compared with the rural area and higher for women than for men (Table 5). Mean diastolic blood pressure was lower in the main city than in the other locations, while systolic pressure showed no significant difference. Systolic and diastolic blood pressure was significantly higher in women than in men. HDL-C was significantly lower in men than in women, and in the main city compared with the other locations, but mean HDL-C values were generally high (above $1.0 \mathrm{mmol} / \mathrm{l}$ ). The TC:HDL-C ratio was significantly higher in the large city, 
Table 3. Diet quality scores and their components by location and sex

(Mean values and standard deviations)

\begin{tabular}{|c|c|c|c|c|c|c|c|c|}
\hline & \multirow[b]{2}{*}{$\begin{array}{c}\text { All } \\
(n 541)\end{array}$} & \multicolumn{4}{|c|}{ Location } & \multicolumn{3}{|c|}{ Sex } \\
\hline & & $\begin{array}{c}\text { Rural } \\
(n 170)\end{array}$ & $\begin{array}{c}\text { Small town } \\
(n 171)\end{array}$ & $\begin{array}{l}\text { Large city } \\
\text { (n 200) }\end{array}$ & $P$ & $\begin{array}{l}\text { Men } \\
(n 271)\end{array}$ & $\begin{array}{l}\text { Women } \\
(n 270)\end{array}$ & $P$ \\
\hline \multicolumn{9}{|l|}{ Diet quality scores } \\
\hline Micronutrient adequacy & & & & & $<0.001$ & & & NS \\
\hline Mean & 8.72 & $11 \cdot 3^{\mathrm{a}}$ & $10 \cdot 8^{\mathrm{a}}$ & $8 \cdot 48^{\mathrm{b}}$ & & 8.72 & $8 \cdot 72$ & \\
\hline SD & 0.2 & 0.2 & 0.9 & 0.2 & & 0.2 & 0.3 & \\
\hline Prevention & & & & & $<0.001$ & & & NS \\
\hline Mean & $5 \cdot 67$ & $6 \cdot 12^{\mathrm{a}}$ & $6 \cdot 11^{a}$ & $5 \cdot 62^{\mathrm{b}}$ & & 5.69 & 5.639 & \\
\hline SD & 0.3 & 0.8 & 0.0 & 0.3 & & 0.04 & 0.6 & \\
\hline \multicolumn{9}{|c|}{ Proportion of subjects meeting the RNI $(\%)^{*}+$} \\
\hline $\mathrm{Mg}$ & 99.8 & 100 & 100 & $99 \cdot 8$ & NS & $99 \cdot 6$ & 100 & NS \\
\hline Vitamin C & $98 \cdot 9$ & 100 & $99 \cdot 7$ & $98 \cdot 8$ & NS & 97.9 & 100 & $<0.001$ \\
\hline Vitamin A & $97 \cdot 4$ & 100 & 99.5 & $97 \cdot 2$ & NS & $96 \cdot 3$ & $98 \cdot 8$ & 0.034 \\
\hline Vitamin $\mathrm{B}_{6}$ & $97 \cdot 3$ & 100 & 100 & $97 \cdot 0$ & NS & 97.5 & $97 \cdot 0$ & NS \\
\hline Thiamin & $84 \cdot 0$ & $97 \cdot 8$ & 98.9 & 82.5 & $<0.001$ & $83 \cdot 1$ & 84.9 & NS \\
\hline Folate & $80 \cdot 2$ & $75 \cdot 9$ & 65.5 & $81 \cdot 0$ & 0.003 & 85.5 & $74 \cdot 2$ & 0.004 \\
\hline Niacin & 69.5 & $97 \cdot 6$ & $97 \cdot 4$ & $66 \cdot 7$ & $<0.001$ & $67 \cdot 9$ & 71.5 & NS \\
\hline Riboflavin & 64.4 & $86 \cdot 3$ & $80 \cdot 3$ & $62 \cdot 4$ & $<0.001$ & $63 \cdot 6$ & 65.4 & NS \\
\hline Pantothenic acid & $61 \cdot 6$ & $85 \cdot 0$ & $81 \cdot 7$ & $59 \cdot 3$ & $<0.001$ & $63 \cdot 3$ & $59 \cdot 6$ & NS \\
\hline $\mathrm{Fe}$ & $46 \cdot 0$ & $71 \cdot 8$ & $62 \cdot 8$ & $43 \cdot 7$ & 0.001 & $55 \cdot 4$ & $35 \cdot 2$ & 0.019 \\
\hline $\mathrm{Ca}$ & $28 \cdot 0$ & 78.9 & 73.4 & $23 \cdot 1$ & $<0.001$ & $27 \cdot 6$ & 28.5 & NS \\
\hline $\mathrm{Zn}$ & $19 \cdot 4$ & $70 \cdot 4$ & $66 \cdot 1$ & 14.4 & $<0.001$ & 14.0 & 25.5 & 0.033 \\
\hline Vitamin E & $16 \cdot 3$ & 30.4 & $25 \cdot 3$ & $15 \cdot 0$ & NS & $10 \cdot 4$ & $23 \cdot 0$ & 0.016 \\
\hline Vitamin $B_{12}$ & 9.1 & $35 \cdot 1$ & 33.5 & 6.5 & $<0.001$ & 9.9 & $8 \cdot 2$ & NS \\
\hline \multicolumn{9}{|c|}{ Proportion of subjects complying with dietary guidelines for chronic disease prevention $(\%)^{\star} \ddagger$} \\
\hline Protein $(>10 \% \mathrm{TE})$ & 99.3 & $98 \cdot 7$ & $97 \cdot 3$ & $99 \cdot 4^{+}$ & NS & $99 \cdot 4$ & $99 \cdot 2$ & NS \\
\hline Cholesterol $(<300 \mathrm{mg} / \mathrm{d})$ & $99 \cdot 1$ & 99.8 & 99.5 & $99 \cdot 0$ & NS & $98 \cdot 8$ & 99.5 & NS \\
\hline SFA (10-15\% TE) & 98.6 & 95.4 & 94.9 & $99 \cdot 0$ & 0.045 & 98.9 & $98 \cdot 3$ & NS \\
\hline Sugar $(<10 \% \mathrm{TE})$ & $91 \cdot 2$ & $92 \cdot 6$ & $91 \cdot 7$ & $91 \cdot 1$ & NS & 91.4 & 91.0 & NS \\
\hline Fibre $(>25 \mathrm{~g} / \mathrm{d})$ & $80 \cdot 8$ & 99.4 & $97 \cdot 0$ & $79 \cdot 0$ & $<0.001$ & $92 \cdot 3$ & $67 \cdot 7$ & 0.002 \\
\hline Fat $(15-30 \%$ TE) & $64 \cdot 6$ & $82 \cdot 7$ & 88.4 & $62 \cdot 6$ & $<0.001$ & 54.2 & $76 \cdot 5$ & 0.006 \\
\hline Fruits and vegetables $(\geq 400 \mathrm{~g} / \mathrm{d})$ & $29 \cdot 3$ & $23 \cdot 6$ & $15 \cdot 8$ & $30 \cdot 2$ & 0.031 & $32 \cdot 3$ & 25.9 & NS \\
\hline PUFA (>10\% TE) & 3.5 & $19 \cdot 9$ & $25 \cdot 2$ & 1.7 & 0.002 & $2 \cdot 1$ & $5 \cdot 2$ & 0.008 \\
\hline
\end{tabular}

RNI, recommended nutrient intake; TE, total energy of the diet.

${ }^{a, b}$ Mean values with unlike superscript letters were significantly different $(P<0.05$; one-way ANOVA test).

* Percentages on weighted data.

†Components of the micronutrient adequacy score.

$¥$ Components of the preventive diet score (against chronic diseases).

but there was no sex difference. HOMA was not different according to location or sex. Mean values for men and women separately by location reveal different patterns. In men, there were significant differences across locations for all risk markers except systolic blood pressure and HOMA. BMI and WC were lower in rural subjects, while diastolic blood pressure was lower in the large city. The cholesterol profile was more favourable in the small town, with higher HDL-C and lower TC:HDL-C ratio, compared with rural or metropolitan subjects. In women, only BMI and cholesterol varied significantly across locations. BMI increased with urbanisation level, and much more so than in men, but WC did not show this pattern. Similarly, HDL-C decreased while the TC:HDL-C ratio increased with urbanisation.

\section{Association of cardiometabolic risk markers with socio-economic status, urbanisation and diet quality}

Table 6 shows the standardised $\beta$-coefficients for the multiple regression models of the cardiometabolic risk markers on SES and location as the index of urbanisation (model 1).
Diet quality scores were added in model 2, along with other lifestyle components (physical activity and alcohol). It was observed that in model 2 , the explained variance of cardiometabolic risk markers increased, especially for obesity markers (BMI and WC).

There was a negative association of education with insulin resistance (HOMA), but only for primary education as opposed to no education. Middle or higher income was associated with higher BMI and WC, compared with lower income. Similarly, living in the main city or small town was independently associated with a higher BMI and WC than living in a village. Residence in the main city was associated with lower HDL-C and higher TC:HDL-C ratio, but only in model 1, whereas it was negatively associated with blood pressure, but only in model 2 . In both models, paradoxically, living in the small town, but not in the large city, was associated with higher insulin resistance (HOMA) compared with rural residence. The micronutrient adequacy score was positively associated with HDL-C and negatively with the TC:HDL-C ratio (model 2). The preventive diet score, however, showed no significant association with cardiometabolic 
risk markers. Physical activity was independently associated with lower BMI, WC and blood pressure, while alcohol consumption was associated with higher BMI, WC and somewhat higher insulin resistance.

\section{Discussion}

Relationship of diet with urbanisation and socio-economic status

The present study in apparently healthy Benin adults showed that diet in the more urbanised area was less preventive against chronic diseases and also less adequate in micronutrients than in less urbanised areas, controlling for income. While the former observation was expected as typical of the nutrition transition $^{(3)}$, the latter is surprising, as it is recognised that diets are usually more diversified in cities (confirmed in the present study; data not shown), and hence more likely to be adequate in micronutrients. However, differences across locations in the bioavailability of dietary micronutrients cannot be ascertained in the absence of more direct measures of micronutrient status. Additionally, diet quality was more closely dependent on income in the large city. Of note is the association of education with a more preventive diet, suggesting that more educated people may be more health conscious.

The present observations regarding the higher intake of meat/poultry and dairy products, but the lower intake of cereals, legumes and fruits in the main city compared with the small town and the rural area reflect the process of dietary transition, particularly in connection with urbanisation and globalisation $^{(2)}$. The association between residence in the main city and the intake of most food groups controlling for SES confirms that dietary transition in Benin is largely a function of urbanisation, as reported in other developing countries $^{(3,14)}$. There was a positive association between residence in the main city and the intake of vegetables, which may reflect greater availability in this context. Note that the consumption of vegetables in a context of dietary transition may also reflect the retention of certain aspects of the traditional diet or the blending of traditional and 'Westernised' foods, as previously cited for Benin ${ }^{(18)}$ and South Africa ${ }^{(14)}$. High consumption of other traditional foods, including roots/tubers, confirms the strong presence of traditional eating habits in Benin, even in the main city ${ }^{(37)}$.

Food consumption in the small town was similar to that of the main city only for meat/poultry; it was, however, closer to rural patterns for most other food groups. The small town resembled the rural area more than the large city for diet quality both in terms of micronutrient adequacy and prevention scores. Rapid urban growth, the influence of various food cultures, the presence of several food markets and supermarkets, and the convenient street foods all contribute to distinctive eating patterns in large metropolitan areas ${ }^{(38,39)}$.

Income level in turn modulates dietary transition, as was shown in the present study by the positive and independent association of income (proxy) with meat/poultry, egg, fish/seafood and tuber/root consumption, and its negative 


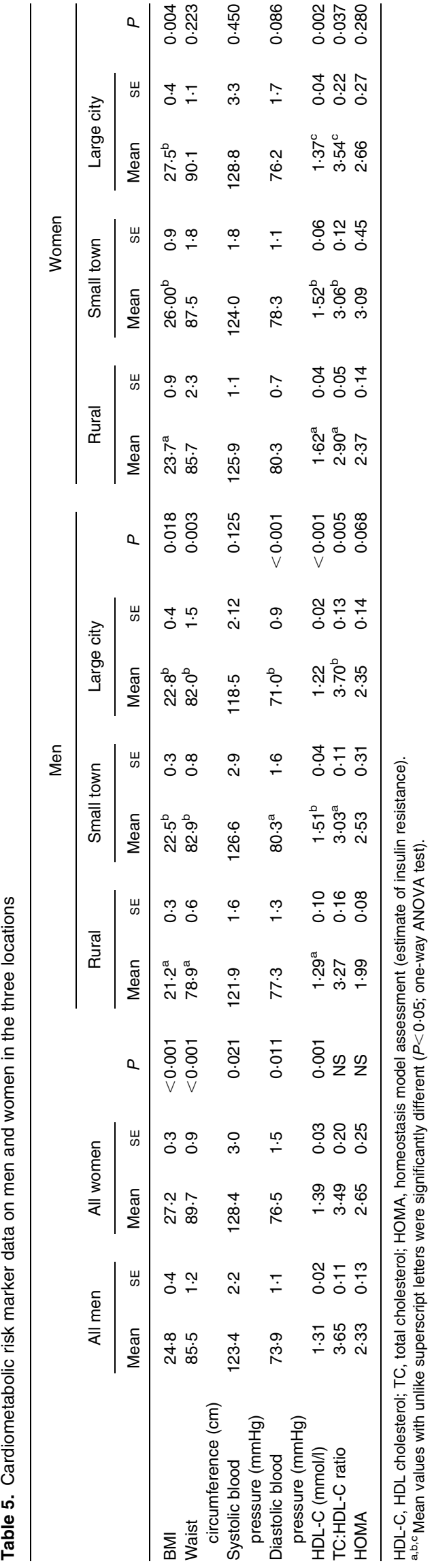

association with cereal consumption. In the case of meat/ poultry and eggs, economic access mediates consumption. This is less the case for fish/seafood, which is widely available and therefore accessible in these coastal areas. Income elasticity of food consumption was especially marked in the main city. In rural areas, and also in small towns to a certain extent, traditional hunting and fishing, domestic husbandry of large and small animals, food collected in the wild and subsistence agriculture help reduce the economic dependence of diet.

Income, however, was not independently associated with diet quality scores, whereas education was positively associated with the preventive diet score. Education is a determinant of food choice, and the relationship between education and the consumption of vegetables and fish, as demonstrated elsewhere ${ }^{(40,41)}$, was also verified in the three Beninese locations. Of note, vegetable (and fruit) intake was a component of the preventive diet score, and so were PUFA, of which fish is a good source. The independent and positive association observed between education and the consumption of dairy products is also consistent with previous studies ${ }^{(42)}$. The positive role of education independent of income, as shown in the present study, suggests that dietary patterns may be improved through education even in resource-limited populations.

\section{Cardiometabolic risk markers and their independent association with diet and other lifestyle factors}

The study confirmed the existence of a positive rural-urban gradient for cardiometabolic risk markers for overall and abdominal obesity, and for the TC:HDL-C ratio (negative gradient for HDL-C); there was no such gradient for blood pressure.

The present observation of higher BMI and WC, as well as higher TC:HDL-C ratio (and lower HDL-C) in the main city, where the nutrition transition is more advanced, supports, although only partly, our hypothesis of a positive ruralurban gradient of cardiometabolic risk because of the diet. Higher diet quality in terms of micronutrient adequacy was indeed independently and significantly associated with a better cholesterol profile. However, BMI and WC were not directly associated with diet variables. On the one hand, a significant relationship of dietary intake to obesity status is seldom observed in cross-sectional studies. On the other hand, energy intake and energy expenditure data would more likely reveal a link with obesity than diet quality scores as used in the present study, or than dietary patterns. In the same population, a significant association of dietary patterns derived by cluster analyses with insulin resistance has been reported, but not with obesity ${ }^{(43)}$. The strong and negative correlation of physical activity with BMI and WC, along with the high prevalence of obesity (global and abdominal), particularly in women, provides some indirect evidence of a positive energy balance, at least among city women. However, the fact that the positive association of BMI and WC with residence in the large city or small town remained significant in the multivariate models, controlling for SES, diet quality and other lifestyle components including physical activity, 
Table 6. Associations between cardiometabolic risk markers, socio-economic status (SES) and location, diet quality and other lifestyle componentsł

\begin{tabular}{|c|c|c|c|c|c|c|c|}
\hline & $\mathrm{BMI}$ & WC & SBP§ & DBP§ & HDL-C§ & TC:HDL-C ratio§ & HOMA§ \\
\hline \multicolumn{8}{|l|}{ Model 1} \\
\hline Adjusted $R^{2}$ & $0 \cdot 271$ & 0.246 & 0.165 & 0.189 & $0 \cdot 120$ & $0 \cdot 161$ & 0.142 \\
\hline$P$ & $<0.001$ & $<0.001$ & $<0.001$ & $<0.001$ & $<0.001$ & $<0.001$ & $<0.001$ \\
\hline \multicolumn{8}{|l|}{ Education } \\
\hline Secondary $v$. none & $0.055 \|$ & 0.017 & -0.019 & 0.009 & 0.060 & -0.073 & -0.015 \\
\hline Primary $v$. none & 0.060 & 0.032 & -0.001 & 0.042 & 0.033 & -0.070 & $-0.093 \dagger$ \\
\hline \multicolumn{8}{|l|}{ Income tertile } \\
\hline High v. low & $0.251^{\star \star \star}$ & $0.251^{\star * *}$ & -0.050 & -0.019 & -0.057 & $0.146^{\star \star}$ & -0.026 \\
\hline Middle $v$. low & $0 \cdot 147^{\star \star}$ & $0.137^{\star \star}$ & -0.054 & -0.048 & 0.057 & 0.041 & -0.044 \\
\hline \multicolumn{8}{|l|}{ Location } \\
\hline Large city $v$. rural & $0.275^{\star \star \star}$ & $0.179^{\star \star \star}$ & -0.099 & -0.315 & $-0.240^{\star \star \star}$ & $0 \cdot 178^{\star *}$ & 0.049 \\
\hline Small town $v$. rural & $0.176^{\star * \star}$ & $0.115^{\star}$ & -0.045 & -0.057 & 0.036 & -0.075 & $0.108^{*}$ \\
\hline \multicolumn{8}{|l|}{ Model 2} \\
\hline Adjusted $R^{2}$ & 0.292 & 0.291 & 0.175 & 0.202 & 0.125 & $0 \cdot 171$ & 0.143 \\
\hline$P$ & $<0.001$ & $<0.001$ & $<0.001$ & $<0.001$ & $<0.001$ & $<0.001$ & $<0.001$ \\
\hline \multicolumn{8}{|l|}{ Education } \\
\hline Secondary $v$. none & 0.042 & 0.002 & -0.018 & 0.008 & 0.060 & -0.077 & -0.017 \\
\hline Primary v. none & 0.047 & 0.013 & -0.001 & 0.035 & 0.036 & -0.078 & $-0.102 \dagger$ \\
\hline \multicolumn{8}{|l|}{ Income level } \\
\hline High $v$. low & $0.241^{\star \star \star}$ & $0.241^{\star \star \star}$ & -0.059 & -0.026 & -0.048 & $0 \cdot 137^{\star \star}$ & -0.020 \\
\hline Middle $v$. low & $0.143^{\star \star}$ & $0.132^{\star \star}$ & -0.057 & -0.050 & 0.059 & 0.039 & -0.043 \\
\hline \multicolumn{8}{|l|}{ Location } \\
\hline Large city $v$. rural & $0.227^{\star \star \star}$ & $0.105 \dagger$ & $-0.174^{\star \star}$ & $-0.406^{\star \star *}$ & -0.166 & 0.093 & 0.024 \\
\hline Small town $v$. rural & $0.182^{\star \star \star}$ & $0.122^{* *}$ & -0.049 & -0.059 & 0.050 & $-0.089 \S$ & $0.116^{*}$ \\
\hline \multicolumn{8}{|l|}{ Diet quality } \\
\hline Micronutrient adequacy score & 0.031 & 0.007 & -0.018 & -0.048 & $0.107^{\star}$ & $-0.139^{\star \star}$ & -0.005 \\
\hline Preventive diet score & 0.022 & 0.008 & -0.037 & -0.035 & -0.004 & 0.028 & -0.028 \\
\hline \multicolumn{8}{|l|}{ Lifestyle } \\
\hline Alcohol intake & $0.071 \dagger$ & $0.108^{\star *}$ & -0.020 & 0.021 & 0.033 & -0.007 & $0.079 \dagger$ \\
\hline Physical activity & $-0.153^{\star \star *}$ & $-0.168^{\star \star \star}$ & $-0.144^{\star *}$ & $-0.144^{\star *}$ & 0.051 & -0.051 & -0.031 \\
\hline
\end{tabular}

WC, waist circumference; SBP, systolic blood pressure; DBP, diastolic blood pressure; TC, total cholesterol; HOMA, homeostasis model assessment (estimate of insulin resistance).

${ }^{\star} P<0.05 ;{ }^{\star *} P<0.01 ;{ }^{* \star *} P<0.001$.

$+0.10>P>0.05$.

$\ddagger$ Multiple linear regression models are adjusted for age and sex. Model 1, SES + location; model 2 , SES + location + diet quality scores + other lifestyle components.

$\S$ Models are also adjusted for BMI.

\| Standardised $\beta$-coefficients.

suggests that environmental risk factors other than diet and lifestyle may be at play in the urban setting, as discussed elsewhere $^{(21,22)}$.

Blood pressure was negatively associated with residence in the main city only when controlling for diet quality and lifestyle. This independent association of residence in the large city and lower blood pressure suggests that variables other than the ones measured in the present study are implicated, including genetic and family factors, and perhaps also nutritional status early in life ${ }^{(44)}$. Physical activity was found to be protective of high blood pressure in the study areas ${ }^{(21,22)}$, and more generally, the benefit of physical activity is well known ${ }^{(45,46)}$. However, lifestyles were more sedentary among large city dwellers than in the small town or rural areas, and therefore physical activity does not explain the blood pressure differential.

In contrast to blood pressure, the positive association between large city residence and high TC:HDL-C ratio (and low HDL-C) was no longer significant in the multivariate model controlling for diet quality and other lifestyle factors. The association appears mediated by micronutrient adequacy of diet, which was positively associated with HDL-C and negatively with the TC:HDL-C ratio. Indeed, we found that the intake of eight micronutrients (four vitamins and four minerals) out of the fourteen included in the score was negatively correlated with the TC:HDL-C ratio (and positively with HDL-C) in univariate models (data not shown). The relationship between micronutrient intake or status and cardiometabolic risk in developing countries is an area where further research is needed, considering the high prevalence of several micronutrient deficiencies including $\mathrm{Zn}$, vitamin $\mathrm{E}$, vitamin $\mathrm{B}_{12}$ and folate ${ }^{(4)}$, as we can suspect in the present study considering observed dietary inadequacies.

Residence in the small town, and not in the large city, was significantly associated with higher insulin resistance in multivariate models, whether or not diet quality and other lifestyle components were included. An association of large city living with insulin resistance may be masked by a more effective diagnosis of diabetes in the large city than in the small town. Indeed, only subjects without a prior diagnosis of diabetes, hypertension or CVD were included in the study. The number of subjects who were excluded from the study because of a prior diagnosis of diabetes was three times as high in the large city as in the other locations (thirty-three $v$. nine subjects). Among the other lifestyle factors, only alcohol 
consumption tended to be positively associated with higher HOMA. A similar association has been reported previously ${ }^{(47)}$.

The significant contribution of income to cardiometabolic risk associated with high BMI, WC and the TC:HDL-C ratio was independent of location, diet and lifestyle. Since income was a significant determinant of consumption of some food groups, diet may be an intermediate factor linking income and cardiometabolic risk, although the composite scores of diet quality did not vary according to income. The positive correlation of the consumption of meat/poultry, dairy products and sweets/sweet drinks with BMI, WC and the TC:HDL-C ratio, on the one hand, and with income, on the other hand (data not shown), makes this explanation plausible.

Education (primary only) tended to be associated with lower HOMA, and this trend was independent of lifestyle. The fact that education was positively and significantly related to fish/seafood consumption, which was itself negatively correlated with HOMA, suggests that fish consumption might partly explain the association of education with less insulin resistance. The positive impact of fish consumption on insulin resistance and CVD has been recognised ${ }^{(48)}$. However, the lack of association of higher education with less insulin resistance cannot be explained.

The present study is the first to describe the characteristics of diet in relation to cardiometabolic risk according to urbanisation level and SES in West Africa. However, it has certain limitations. In cross-sectional studies such as the present one, causality cannot be inferred and only associations can be described. Furthermore, the study was conducted in the coastal zone of Benin. The results are therefore only representative of this part of the country. Measuring dietary intakes with only two (in some instances, three) $24 \mathrm{~h}$ recalls is another limitation. Furthermore, cardiometabolic risk may also be increased by undernutrition early in life, as well as by several micronutrient deficiencies ${ }^{(16,17,21)}$, including $\mathrm{Zn}$, vitamin $\mathrm{E}$ and folate $^{(4)}$. Longitudinal studies would be required in Africa in order to identify the portion of risk that can be attributed to nutrition in early life and that which is associated with dietary shifts typical of the nutrition transition and with concurrent micronutrient deficiencies. Finally, the absence of an association between the preventive diet score and cardiometabolic risk markers suggests that this indicator should be re-examined, perhaps using a graduated rather than dichotomous scale. However, we tested as an alternative the Diet Quality Index International ${ }^{(49)}$ in part of the data, and no significant association with cardiometabolic risk was observed, which is at variance with our micronutrient adequacy score.

\section{Conclusion}

The present study on the relationship of urbanisation and SES with nutrition transition and cardiometabolic risk confirms the existence of a higher cardiometabolic risk in a large African city than in a small town and rural area, except for blood pressure. The difference can partly be ascribed to a more advanced stage of nutrition transition, and associated lower diet quality and less physical activity, in the large city. Diet quality was not associated with obesity markers, while higher micronutrient adequacy was associated with a more favourable cholesterol profile. Cardiometabolic risk could be mitigated by policies and programmes promoting a more adequate diet, particularly with regard to micronutrient intake, and a more active lifestyle, through behavioural change strategies coupled with conducive environmental measures.

\section{Acknowledgements}

This study was supported by grants from the Canadian Institutes of Health Research. The contribution of the authors was as follows: H. D. designed the research project and wrote the manuscript on the basis of a rough draft prepared by G. N.-B. G. N.-B. and R. S. developed the study protocol, collected the data in Benin and analysed the data as part of their $\mathrm{PhD}$ programme. V. A. and B. F. as co-investigators supervised the field work and contributed to the critical revision of the manuscript. The authors declare no conflict of interest related to this study.

\section{References}

1. Drewnowski A \& Popkin BM (1997) The nutrition transition: new trends in the global diet. Nutr Rev 55, 31-43.

2. Vorster HH, Bourne LT, Venter CS, et al. (1999) Contribution of nutrition to the health transition in developing countries: a framework for research and intervention. Nutr Rev 57, 341-349.

3. Popkin BM (1999) Urbanization, lifestyle changes and the nutrition transition. World Dev 27, 1905-1916.

4. Eckhardt CL (2006) Micronutrient Malnutrition, Obesity, and Chronic Disease in Countries Undergoing the Nutrition Transition: Potential Links and Program/policy Implications. Washington, DC: International Food Policy Research Institute, (FCND discussion paper 213).

5. United Nations System (2006) Diet-related chronic diseases and the double burden of malnutrition in West Africa. SCN News 33, 3-43.

6. Delisle H \& Receveur O (2007) Les "dysnutritions" dans les pays en développement ('Dysnutrition' in developing countries). Can Med Assoc J 176, 65.

7. WHO/FAO Expert Consultation (2003) The global burden of chronic diseases. In Diet, Nutrition and the Prevention of Chronic Diseases. Report of a WHO/FAO Expert Consultation. Geneva: World Health Organization.

8. Monteiro CA, Conde WL \& Popkin BM (2001) Independent effects of income and education on the risk of obesity in the Brazilian adult population. J Nutr 131, 881S-886S.

9. Monteiro CA, Conde WL \& Popkin BM (2002) Is obesity replacing or adding to undernutrition? Evidence from difference social classes in Brazil. Public Health Nutr 5, 105-112.

10. Popkin B (2002) The shift in stages of the nutrition transition in the developing world differs from past experiences!. Public Health Nutr 5, 205-214.

11. Popkin BM, Keyou G, Zhai F, et al. (1993) The nutrition transition in China: a cross-sectional analysis. Eur J Clin Nutr $\mathbf{4 7}$, 333-346.

12. Rivera JA, Barquera S, Campirano F, et al. (2002) Epidemiological and nutritional transition in Mexico: rapid increase of non-communicable chronic diseases and obesity. Public Health Nutr 5, 113-122. 
13. Smit W (1998) The rural linkages of urban households in Durban, South Africa. Environ Urban 10, 77-88.

14. Steyn K, Kazenellenbogen JM, Lombard CJ, et al. (1997) Urbanization and the risk of chronic diseases and lifestyle in the black population of the Cape Peninsula, South Africa. J Cardiovasc Risk 4, 135-142.

15. Vorster HH, Venter CS, Wissing MP, et al. (2005) The nutrition and health transition in the North West Province of South Africa: a review of the THUSA (Transition and health during urbanisation of South Africans) study. Public Health Nutr 8, 480-490.

16. Vorster HH (2002) The emergence of cardiovascular disease during urbanisation of Africans. Public Health Nutr 5, 239-243

17. Garrett JL \& Ruel M (2003) Stunted Child-overweight Mother Pairs: An Emerging Policy Concern? Washington, DC: International Food Policy Research Institute, Food Consumption and Nutrition Division (discussion paper no. 148).

18. Ntandou G, Fayomi B \& Delisle H (2005) Malnutrition infantile et surpoids maternel dans des ménages urbains pauvres au Bénin (Child malnutrition and maternal overweight in poor urban households in Benin). Cabiers Santé $\mathbf{1 5}$, $263-270$

19. Sodjinou RS, Agueh V, Fayomi B, et al. (2009) Dietary patterns of urban adults in Benin: relationship with overall diet quality and socio-demographic characteristics. Eur $J$ Clin Nutr 63, 222-228.

20. Sodjinou R, Agueh V, Fayomi B, et al. (2008) Obesity and cardio-metabolic risk factors in urban adults of Benin: relationship with socio-economic status, urbanisation, and lifestyle patterns. BMC Public Health 8, 84 .

21. Ntandou G, Delisle H, Agueh V, et al. (2008) Physical activity and socioeconomic status explain rural-urban differences in obesity: a cross-sectional study in Benin (West Africa). Ecol Food Nutr 47, 1-25.

22. Ntandou G, Delisle H, Agueh V, et al. (2009) Abdominal obesity explains the positive rural-urban gradient in the prevalence of the metabolic syndrome in Benin, West Africa. Nutr Res 29, 180-189.

23. INSAE (2002) Troisième recensement général de la population et de l'habitat (Third General Census of Population and Housing). Cotonou: Institut national de la statistique et de l'analyse économique.

24. INSAE/DHS (2001) Enquête démographique et de santé du Bénin 2001, rapport final (Demographic and Health Survey of Benin, 2001, Final Report). Cotonou: Institut National de Statistique et d'Analyse Économique.

25. Calloway D, Murphy S \& Bunch S, et al. (2006) World Food 2 Dietary Assessment System. http://www.fao.org/infoods

26. Barikmo I, Ouattara F \& Oshaug A (2004) Table de composition d'aliments du Mali (Food Composition Table of Mali). Oslo: Akerhus University College.

27. Oguntona E \& Akinyele IO (1995) Nutrient Composition of Commonly Eaten Foods in Nigeria - Raw, Processed and Prepared. Ibadan: Food Basket Foundation International.

28. Ponce X, Ramirez E \& Delisle H (2006) A more diversified diet among Mexican men may also be more atherogenic. J Nutr 136, 2921-2927.

29. Désilets MC, Rivard M, Shatenstein B, et al. (2007) Dietary transition stages based on eating patterns and diet quality among Haitians of Montreal, Canada. Public Health Nutr 10, $454-463$.

30. FAO/WHO (2001) Human Vitamin and Mineral Requirements. Report of a Joint FAO/WHO Expert Consultation. Rome: FAO.
31. WHO/FAO Expert Consultation (2003) Diet, Nutrition and the Prevention of Chronic Diseases. Report of a WHO/FAO Expert Consultation. Geneva: WHO.

32. Ainsworth BE, Haskell WL, Whitt MC, et al. (2000) Compendium of physical activities: an update of activity codes and MET intensities. Med Sci Sports Exerc 32, S498-S504.

33. WHO/FAO Expert Consultation (2003) Recommendations for preventing cardiovascular diseases. In Diet, Nutrition and the Prevention of Chronic Diseases. WHO/FAO Expert Consultation. Geneva: WHO

34. WHO (2006) The WHO Stepwise Approach to Surveillance of Noncommunicable Diseases (Steps). STEPS Instruments for NCD Risk Factors (Core and Expanded Version 1.4). www.who.int/ncd_surveillance

35. Matthews DR, Hosker JP, Rudenski AS, et al. (1985) Homeostasis model assessment: insulin resistance and beta-cell function from fasting plasma glucose and insulin concentrations in man. Diabetologia 28, 412-419.

36. Department of Statistics and Center for Agricultural and Rural Development (1996) Software for Intake Distribution Estimation (SIDE) v.1.O. Ames, IA: Iowa State University.

37. Elwert-Kretschmer K (2001) L'aspiration au changement alimentaire à Cotonou, Bénin (The Desire to Change Diet in Cotonou, Benin). Montpellier: CIRAD.

38. Ruel MT, Haddad L \& Garrett JL (1999) Some urban facts of life: implications for research and policy. World Dev 27, 1917-1938.

39. FAO (1997) L'alimentation de rue. Rapport d'une réunion technique de la FAO sur l'alimentation de rue, Calcutta, Inde, 6-9 novembre 1995 (Street Food. Report of an FAO Technical Meeting on Street Foods, Calcutta, India, 6-9 November 1995). Rome: FAO.

40. Barker M, Lawrence W, Woadden J, et al. (2008) Women of lower educational attainment have lower food involvement and eat less fruit and vegetables. Appetite 50, 464-468.

41. Murakami K, Miyake Y, Sasaki S, et al. (2009) Education, but not occupation or household income, is positively related to favorable dietary intake patterns in pregnant Japanese women: the Osaka Maternal and Child Health Study. Nutr Res 29, 164-172.

42. Deshmukh-Taskar P, Nicklas TA, Yang SJ, et al. (2007) Does food group consumption vary by differences in socioeconomic, demographic, and lifestyle factors in young adults? The Bogalusa Heart Study. J Am Diet Assoc 107, 223-234.

43. Delisle H (2010) Findings on dietary patterns in different groups of African origin undergoing nutrition transition. Appl Physiol Nutr Metab 35, 224-228.

44. Opie LH \& Seedat YK (2005) Hypertension in Sub-saharan African populations. Circulation 112, 3562-3568.

45. Forrest KY, Bunker CH, Kriska AM, et al. (2001) Physical activity and cardiovascular risk factors in a developing population. Med Sci Sports Exerc 33, 1598-1604.

46. Sobngwi E, Mbanya JC, Unwin NC, et al. (2002) Physical activity and its relationship with obesity, hypertension and diabetes in urban and rural Cameroon. Int $J$ Obes Relat Metab Disord 26, 1009-1016.

47. Shah JH (1988) Alcohol decreases insulin sensibility in healthy subjects. Alcohol 23, 103-109.

48. Kris-Etherton PM, Harris WS, Appel LJ, et al. (2002) Fish consumption, fish oil, omega-3 fatty acids, and cardiovascular disease. Circulation 106, 2747-2757.

49. Kim S, Haines PS, Siega-Riz AM, et al. (2003) The Diet Quality Index-International (DQI-I) provides an effective tool for cross-national comparison of diet quality as illustrated by China and the United States. J Nutr 133, 3476-3484. 